Journal of Research in Interprofessional

Practice and

Education

Vol. 8.1

2018

\title{
Emotional Intelligence and Teamwork Skills Among Undergraduate Engineering and Nursing Students: A Pilot Study
}

\author{
Charlotte T. Lee, RN, CON(C), PhD, Ryerson University \\ Michele Bristow, PhD, EIT, University of Waterloo \\ Jason C. Wong, MD, University of Toronto
}

\begin{abstract}
Background: Healthcare operations require collaboration between healthcare and non-healthcare professionals.

Objectives: To examine: a) the effectiveness of a case-based interprofessional education (IPE) workshop, and b) the association between emotional intelligence (EI) and teamwork skills in nursing and industrial engineering trainees.

Methods: Undergraduate nursing and industrial engineering students $(N=42)$ participated in a workshop that requires the integration of knowledge from both disciplines. Previously validated instruments were used to assess EI, empathic listening and teamwork skills pre- and post-workshop.

Findings: While results of the multivariate analysis of variance suggested no difference in study variables before and after the workshop, findings from Pearson's correlation revealed more pairs of significant correlations post-workshop. Positive association between EI and teamwork skills was found post-workshop.

Conclusion: IPE workshops beyond conventional healthcare professions are feasible and welcomed by trainees. EI should be considered an antecedent of teamwork.

Keywords: Industrial engineering; Nursing; Interprofessional education; Emotional intelligence; Undergraduate; Teamwork
\end{abstract}

Journal of Research in Interprofessional Practice and Education (JRIPE)

Vol. 8.1

doi: $10.22230 /$ jripe.2018

v8n1a260

(c) 2018

Corresponding author: Charlotte T. Lee. Email: lee.charlotte@ryerson.ca.

\section{Introduction}

Collaborative competencies are recognized as an important skill set in professional training programs [1]. With ongoing efforts, understanding of interprofessional education has grown tremendously in the past few decades. Yet, little is known about enhancing the collaborative skills of healthcare trainees to facilitate work with professionals from non-healthcare disciplines, and vice versa. As human-centred design [2] and participatory design [3] become the standard of practice for health technology innovation, many aspects of healthcare provisions require joint expertise from both healthcare providers and experts in science, technology, engineering, and mathematics (STEM) disciplines. For instance, the design of a healthcare facility is informed by a multidisciplinary team that may consist of industrial and human factors engineers, psychologists, anthropologists, health services researchers, operations researchers, organizational managers, clinicians, and architects [4]. Given the need for interprofessional collaborative skills among healthcare and STEM profes- 
2

Emotional Intelligence and Teamword

Lee, Bristow, \& Wong

Journal of Research in Interprofessional Practice and Education

Vol. 8.1

2018 sionals, this study aims to explore factors associated with developing interprofessional knowledge, skills, and attitudes in undergraduate nursing and industrial engineering students.

Specialization in a particular discipline and separation from people in other disciplines is a common experience for students in an undergraduate program that prepares them for a specific profession. Different professions place different value on particular technical competencies according to the nature of the work of the profession. As the need for health technology innovation increases to meet the needs of society, more value is being placed on the ability to work with people from multiple disciplines spanning health and engineering. Challenges in communication, teamwork, leadership, and conflict resolution abound in an interprofessional context [5]. As a result, there is a need for programs to adapt to these needs and prepare graduates for multidisciplinary teamwork. At its most fundamental level, working in a team requires interpersonal skills that are basically expressed by the ability to selfregulate and empathize. Regulating one's actions according to one's own feelings and those of others is the central tenet of emotional intelligence. While there is currently no consensus on the role of emotional intelligence in collaboration and teamwork, it is worth a closer look to examine potential links to determine antecedents for developing higher-order collaborative competencies.

\section{Background}

Interprofessional education has been established in many academic institutions to enhance one's capacity to work with individuals from different professions. This has been a popular topic among professional programs within healthcare in the past decade. The main goal of interprofessional education is to facilitate interprofessional practice through bridging educational programs, which leads to superior teamwork and ultimately improves outcomes [6,7]. High performance teamwork is characterized by the presence of effective communication and collaboration, mutual accountability, a complementary skill set, a deeper sense of purpose, and relatively more ambitious performance goals compared to the average team [8].

The successful delivery of safe and effective care spans from the usability of medical devices to top-level decision-making processes in healthcare administration and management as well as health-related regulations and policy. For instance, innovations and physical designs are needed to improve the entire process of care for patients. Imagine teams of design experts, such as engineers, architects, and computing specialists, and healthcare professionals, including nurses, physicians, and many others, working together to promote integrated, effective, efficient, and dignified care. Designs from these teams would "emphasize synergy among physical design, care delivery processes, effective workplace culture, and technology" [9, p. 423]. Nevertheless, a scarce amount of literature can be found that examines interprofessional education or practice between healthcare and non-healthcare professionals.

Focusing on the collaboration between design professionals and healthcare professionals, Lamb, Zimring, Chuzi, and Dutcher[9] propose seven domains of interprofessional competency needed to synthesize and integrate the knowledge and skills 
3

Emotional Intelligence and Teamword

Lee, Bristow, \& Wong
Journal of Research in Interprofessional Practice and Education

Vol. 8.1

2018 of these diverse professionals to create better healthcare environments. These domains are: patient centred-care, healthcare systems, integration, innovation, teamwork, the science of integrated health design, and professional knowledge, culture, and tools. These domains have not been validated empirically but are similar to other interprofessional frameworks [1,10]; mastery of each of the seven domains assumes the presence of a certain level of emotional intelligence and interpersonal skills.

Emotional intelligence is defined as an "ability to monitor and regulate one's own and other's feelings, and to use feelings to guide one's thinking and action" [11, p. 189]. According to Goleman [12], emotional intelligence is further translated to five areas of competencies: self-awareness, self-regulation, motivation, empathy, and social skills. In examining the skills required to conduct successful teamwork, Luca and Tarricone [13] identify emotional intelligence as "invisible" teamwork skills. Furthermore, they provide preliminary data that supports a positive correlation between emotional intelligence and team performance. Similarly, Owolabi [14] reports that emotional intelligence and a supportive work climate have positive effects on teamwork skills in Nigerian workers. Among medical students, Hojat, Bianco, Mann, Massello, and Calabrese [15] find that empathy, teamwork, and an integrative approach to patient care are related concepts. On the contrary, a scoping review of interprofessional education and practice excludes emotional intelligence as a relevant factor to interprofessional practice without explanation [16]. And, Clarke [17] reports that while emotional intelligence has a direct and unique effect on one aspect of team processes for Master of Business Administration (MBA) students, this effect is not consistently noted within the study sample.

\section{Theoretical framework}

Luca and Tarricone [13] explore the suggested visible and invisible skills that are needed for teamwork. Among these skills, emotional intelligence and teamwork skills are less visible than generic skills (e.g., time management) or technical skills (e.g., designing, authoring). However, they argue that invisible skills are extremely important for successful teamwork. Table 1 illustrates the framework that guides the inquiry of the present study.

\section{Table 1. Invisible emotional intelligence and teamwork skills underlie visible technical and generic skills for successful interprofessional teams}

\begin{tabular}{|l|l|l|l|l|}
\hline Type of skills & Technical skills & Generic skills & Teamwork skills & Emotional intelligence \\
\hline Examples & $\begin{array}{l}\text { Programming, } \\
\text { design, authoring }\end{array}$ & $\begin{array}{l}\text { Time management, } \\
\text { setting priorities }\end{array}$ & $\begin{array}{l}\text { Collaboration, } \\
\text { communication, negotiation }\end{array}$ & $\begin{array}{l}\text { Empathy, } \\
\text { social skills }\end{array}$ \\
\hline \multicolumn{3}{c}{ Visible skills } \\
\hline
\end{tabular}

Source: Adapted from Luca \& Tarricone [13]. 
4

Emotional Intelligence and Teamword

Lee, Bristow, \& Wong

Journal of Research in Interprofessional Practice and Education

Vol. 8.1

2018
There is continuing interest in investigating emotional intelligence and its potential utility in predicting behavioural and professional outcomes of disparate populations [18]. Luca and Tarricone [13] find a strong correspondence between students' emotional intelligence and team harmony. Furthermore, Farh, Seo, and Tesluk [19] theorize that higher teamwork effectiveness, and subsequently superior job performance, is demonstrated by employees with higher emotional intelligence and perception in job contexts that activate emotional capabilities, such as managerial work. The interprofessional context, particularly in any health-related matters, provides emotion-based cues; against this context, it can similarly be hypothesized that developing emotional intelligence would lead to improvements in teamwork effectiveness in interprofessional teams.

\section{Study purpose and hypotheses}

This study aims to address two gaps in the existing interprofessional literature: first, to examine the effectiveness of a case-based interprofessional workshop for nonhealthcare (industrial engineering) and healthcare (nursing) undergraduate student trainees. Second, to examine the association between emotional intelligence and teamwork skills in trainees within the aforementioned undergraduate professional training programs. The authors hypothesized an increase in emotional intelligence, empathy, teamwork skills, and positive attitude toward interprofessional education following the workshop. It was also hypothesized that emotional intelligence and empathy were positively associated with teamwork skills based on Luca and Tarricone's [13] theoretical framework.

\section{Methods}

\section{Design, setting, and participants}

A quasi-experimental study design was used to address research questions. An interprofessional education workshop was developed for target participants and study variables were assessed via self-report surveys. This study took place in a classroom within a university campus in the province of Ontario, Canada. Undergraduate students $(N=42)$ enrolled in a third-year industrial engineering $(n=34)$ course and a secondyear nursing course $(n=8)$ were recruited to participate in a one-time, two-hour casebased learning workshop. Inclusion criteria were: a) age 18 or above, b) enrolled in a specific undergraduate course in industrial engineering and nursing, and c) able to provide informed consent. There were no exclusion criteria in this study.

\section{Instrumentation}

Study variables of emotional intelligence, empathy, teamwork skills, and perception of interprofessional education were assessed using previously validated questionnaires. A summary of variables, instruments, methods of measurements, and reliability is outlined in Table 2.

Perceived emotional intelligence was assessed with the Emotional Intelligence SelfAssessment [20]. This assessment has 45 items and measures five dimensions of emotional intelligence: self-awareness, managing emotions, self-motivation, relating well, 
Table 2. Summary of study variables and measurements

Emotional Intelligence and Teamword

Lee, Bristow, \& Wong
Journal of Research in Interprofessional Practice and Education

Vol. 8.1

2018

\begin{tabular}{|l|l|l|c|}
\hline Variable & Instrument & $\begin{array}{l}\text { Method of measurement } \\
\text { (Number of items) }\end{array}$ & $\begin{array}{l}\text { Cronbach's } \\
\text { Alpha }\end{array}$ \\
\hline $\begin{array}{l}\text { Perceived emotional } \\
\text { intelligence }\end{array}$ & $\begin{array}{l}\text { Emotional Intelligence Self- } \\
\text { Assessment [20] }\end{array}$ & Self-report survey (45) & 0.95 \\
\hline Active empathetic listening & $\begin{array}{l}\text { Active-Empathic Listening Scale } \\
\text { (AELS) [21]; Peer evaluation scale }\end{array}$ & Self-report survey (11) & 0.84 \\
\hline Empathy & Emotional Empathy Scale [22] & Self-report survey (30) & 0.74 \\
\hline $\begin{array}{l}\text { Perceived readiness for } \\
\text { interprofessional learning }\end{array}$ & $\begin{array}{l}\text { Interdisciplinary Education } \\
\text { Perception Scale (IEPS) [23] }\end{array}$ & Self-report survey (18) & 0.88 \\
\hline $\begin{array}{l}\text { Perceived teamwork } \\
\text { competence (communication, } \\
\text { collaboration) }\end{array}$ & Team Skills Scale [24] & Self-report survey (17) & 0.86 \\
\hline
\end{tabular}

and emotional mentoring. Participants were asked to rate their own ability to display 45 actions or gestures related to emotional intelligence on a scale of 1 to 7 , with 1 being "low ability" and 7 being "high ability." The Cronbach's alpha for this tool was 0.95 .

Perceived active empathetic listening skill was assessed with the Active-Empathic Listening Scale (AELS) [21] and was compared to the peer evaluation scale. The AELS consists of 11 items relating to aspects of active-empathetic listening skills, including sensing, processing, and responding. Participants were asked to rate their own skills on a 7-point Likert scale with 1 being "never or almost never true" to 7 being "always or almost always true." A high rating indicates a higher level of active empathic listening skills. The Cronbach's alpha for this tool was 0.84 .

Perceived ability to feel empathy was measured with a self-reported Emotional Empathy Scale [22]. Participants rated items in the scale that they identified as the most emotionally troublesome. A rating of 1 indicates "strongly disagree" and 5 indicates "strongly agree," and a higher rating indicates a higher level of emotional empathy. The Cronbach's alpha was 0.74 .

Perceived readiness for interprofessional learning was measured by an 18-item Interdisciplinary Education Perception Scale (IEPS) [23]. This survey targets four domains of readiness for interprofessional education: perceived competence and autonomy, perceived need for cooperation, perception of actual cooperation, and perceived understanding of others' value. Participants were asked to respond on a 5point Likert scale, with 1 being "strongly disagree" and 5 being "strongly agree." A higher rating means a more positive opinion toward interprofessional learning. The Cronbach's alpha for this tool was 0.88 .

Perception of teamwork competence was measured using a 17-item Team Skills Scale (TSS) [24]. Participants were asked to rate, on a 5-point scale (from poor to excellent), their perceived ability to carry out teamwork tasks. A higher rating indicates a more positive ability to work in a team setting. The Cronbach's alpha for this tool was 0.86 . 
6

Emotional Intelligence and Teamword

Lee, Bristow, \& Wong

Journal of Research in Interprofessional Practice and Education

Vol. 8.1

2018

\section{Procedure}

Following approval by the research ethics board, eligible participants received study information approximately two to three weeks prior to the study intervention (e.g., the interprofessional workshop). The research assistant made an announcement at the beginning of a lecture that the target study populations were enrolled in and encouraged participation. Eligible participants were given the option to participate in the study intervention but not the survey component of study, and in such cases, informed consent was not needed. To ensure participants did not feel coerced to participate, the research assistant handled study recruitment and informed consent forms. Study investigators who were faculty members and instructors of these nursing and industrial engineering courses were unaware of participants' identity.

The interprofessional workshop lasted approximately two hours and consisted of the following components: a) informed consent, b) complete study questionnaires before the activity, c) group work, d) debriefing, and e) completion of study questionnaires after the activity. The course instructors and an external collaborator, who all had prior experience in facilitation and interprofessional training, facilitated the workshop. For the group work, participants worked in groups of seven to 10 on one case study. Based on a set of captioned photographs of a cancer centre, participants were asked to create a "process map" that outlined a cancer patient's experience when receiving treatment. A case study design is one example of an experiential learning strategy [25] and is frequently employed in interprofessional training [26]. Materials (such as the captioned photographs and prompts) and steps within the process map were developed by the authors and reviewed by content experts from both health and non-health disciplines (see Acknowledgements). Participants from the two programs were randomly and evenly distributed in eight groups, with approximately seven industrial engineering trainees and two nursing trainees per group. The activity provided the opportunity for participants to exchange ideas and expertise while creating this "process map." At the end of the work period, groups presented their final process map to all participants. During debriefing, which is guided by the Plus/Delta Framework [27], participants were led to reflect upon their experience in communicating to professionals with a different background and different roles and responsibilities. Lastly, participants were asked to complete the study questionnaires and provide feedback.

\section{Data analysis}

Quantitative analysis was conducted using Statistical Packages for Social Science (SPSS) version 23 following data cleaning and screening. Repeated measure multivariate analysis of variance (MANOVA) was used to examine the difference in emotional intelligence and teamwork skills before and after the intervention. Due to the small sample size from the nursing participant group, it was not possible to compare differences between the two professional groups. Separate Pearson's correlation tests were performed to examine the association between emotional intelligence and teamwork skills before and after study intervention.

Qualitative feedback was analyzed using thematic analysis [28]. The lead author read the written feedback at the end of each survey to familiarize herself with their 
7

Emotional Intelligence and Teamword

Lee, Bristow, \& Wong

Journal of Research in Interprofessional Practice and Education

Vol. 8.1

2018 content and make observations before formal coding. Summaries of responses were put into tables. Then, the research team worked to identify and code meaningful patterns observed across all comments. Comments were read again carefully to organize meaningful data into groups. Meaningful data could be words that were repeated by many participants or heavily emphasized by any participants-comments expressed with strong emotions or content relevant to the study, based on the researchers' knowledge.

These codes were then further organized into themes by drawing connections between or among codes. This process was guided by considerations of how different codes might combine to form an overarching theme. The resulting themes and subthemes were put into a thematic matrix for review. During the review, themes were examined for coherence (i.e., whether the extracted codes within a theme were coherent) and fit (i.e., whether the themes were appropriate for the dataset). Lastly, the final themes were named and defined. Themes were extracted separately by the lead author and co-author, and disagreements were resolved through discussion with co-authors. The rigour of this study was ensured through careful and detailed documentation and the demonstration of the coding process, the identification of themes, and the review of the final thematic matrix.

\section{Power and sample size considerations}

The sample size of 42 participants is adequately powered for Pearson's correlation and MANOVA. For Pearson's moment correlation, an estimated 95 percent power is estimated with a sample size of 40, alpha of 0.05 (one-tailed), and effect size of $r=0.50$ [29].

There is no commonly agreed upon method to determine power and sample size for MANOVA. Some factors to consider when determining power for MANOVA include: a) the general principles are similar to power calculation of ANOVA where power is dependent on sample size, effect size, and alpha level; b) power is higher when variables are highly correlated; c) power increases with more dependent variables [30]. According to Guildford and Frunchter [31], 80 percent power is estimated in a three-group MANOVA with five variables, a large effect size, alpha of 0.05 , and a sample size of 35 . As the number of the group increases, a larger sample size is needed to maintain the same level of power. For instance, for a four-group MANOVA with the same parameters, 40 subjects will be needed to achieve 80 percent power. Thus, the study's current group size means that the study is likely powered adequately to detect a large effect size.

\section{Results}

\section{Descriptive statistics}

A total of 42 undergraduate students $(N=42)$ participated in the study workshop. Of them, 34 were third-year industrial engineering students and eight were second-year nursing students. Demographic information was not collected from participants. Based on observation, participants from industrial engineering were predominantly male and participants from nursing were predominantly female. This is consistent with the target and sample population [32,33]. 
8

Emotional Intelligence and Teamword

Lee, Bristow, \& Wong

Journal of Research in Interprofessional Practice and Education
As can be seen in Table 3, ratings for study variables were positive overall, even prior to the workshop, indicating that participants in both disciplines were empathic and had high levels of emotional intelligence, acceptance of interprofessional learning, and teamwork skills.

Table 3. Means of study variables

\begin{tabular}{|l|c|c|}
\hline Variable & $\begin{array}{c}\text { Pre-workshop } \\
\text { (Standard Deviation) (N=42) }\end{array}$ & $\begin{array}{c}\text { Post-workshop } \\
\text { (Standard Deviation) (N=42) }\end{array}$ \\
\hline Emotional intelligence\# & $5.19(0.67)$ & $5.13(0.77)$ \\
\hline Active empathic listening\# & $5.41(0.71)$ & $5.21(0.84)$ \\
\hline Emotional empathy* & $3.77(0.47)$ & $3.60(0.39)$ \\
\hline Perception of interprofessional education* & $3.99(0.38)$ & $3.80(0.57)$ \\
\hline Perceived team skills* & $3.67(0.53)$ & $3.63(0.51)$ \\
\hline
\end{tabular}

\#Rating: 1 to 7, the higher the more positive; *Rating: 1 to 5, the higher the more positive

\section{Effectiveness of the case-based interprofessional workshop}

Although the means of all variables decreased in magnitude post-intervention, repeated measure MANOVA showed no differences in study variables before and after the workshop session (Wilks' Lambda $=0.931, \mathrm{~F}(5,71)=1.055, p=0.393$, partial eta-squared $=0.069$ ). Moreover, when testing for the second research question, findings from correlation tests revealed more pairs of significant correlation between emotional intelligence measures and teamwork skills after the workshop (see Table 4). The correlation coefficient also increased after the interprofessional workshop.

\section{Table 4. Pearson's correlation coefficient (effect size, $r$ ) pre- and post-intervention (2-tailed)}

\begin{tabular}{|l|c|c|c|c|c|c|c|c|c|c|}
\hline & \multicolumn{2}{|c|}{$\begin{array}{c}\text { Emotional } \\
\text { intelligence }\end{array}$} & \multicolumn{2}{|c|}{$\begin{array}{c}\text { Active empathic } \\
\text { listening }\end{array}$} & \multicolumn{2}{|c|}{$\begin{array}{c}\text { Emotional } \\
\text { empathy }\end{array}$} & \multicolumn{2}{|c|}{$\begin{array}{c}\text { Interprofessional } \\
\text { learning }\end{array}$} & \multicolumn{2}{|c|}{ Team skills } \\
\hline & Pre & Post $^{2}$ & Pre & Post & Pre & Post & Pre & Post & Pre & Post \\
\hline Emotional intelligence & 1 & 1 & & & & & & & & \\
\hline Active empathic listening & $0.647^{* *}$ & $0.766^{* *}$ & 1 & 1 & & & & & & \\
\hline Emotional empathy & 0.125 & $0.465^{* *}$ & 0.115 & 0.269 & 1 & 1 & & & & \\
\hline Interprofessional learning & 0.089 & $0.633^{* *}$ & $0.333^{* *}$ & $0.685^{* *}$ & 0.023 & $0.375^{* *}$ & 1 & 1 & & \\
\hline Team skills & 0.570 & $0.631^{* *}$ & $0.379^{* *}$ & $0.620^{* *}$ & 0.115 & $0.376^{*}$ & $0.378^{* *}$ & $0.428^{* *}$ & 1 & 1 \\
\hline
\end{tabular}

Notes: 1 pre-intervention; 2 post-intervention; ${ }^{*} p<0.05 ;{ }^{* *} p<0.01$ 
9

Emotional Intelligence and Teamword

Lee, Bristow, \& Wong

Journal of Research in Interprofessional Practice and Education

Vol. 8.1

2018

\section{Association between emotional intelligence measures and teamwork skills}

Pearson's correlations (see Table 4) showed positive and significant correlation between teamwork skills and active empathic listening, both before $(r=0.379, p<0.01)$ and after $(r=0.620, p<0.01)$ the intervention. Following the study intervention, significant and positive correlations were noted between teamwork skills and emotional intelligence $(r=0.631, p<0.01)$ and between teamwork skills and emotional empathy $(r=0.376, p<0.05)$.

For attitude toward interprofessional learning, its association with emotional intelligence and empathy followed a similar pattern: interprofessional learning was correlated with active empathic listening prior to $(r=0.333, p<0.001)$ and after the intervention $(r=0.685, p<0.001)$. Following the intervention, significant associations between interprofessional learning and emotional intelligence $(r=0.633$, $p<0.01)$ and between interprofessional learning and emotional empathy $(r=0.375$, $p<0.001$ ) were noted (see Table 4).

\section{Written feedback from participants}

Six $(n=6)$ participants provided written feedback. Although response was scant, the qualitative feedback reflected that the present approach to introduce collaboration between industrial engineering and nursing students was well received by participants. Their comments addressed four out of the six domains of interprofessional competence specified by inteprofessional practice framework, they are: a) team functioning, b) interprofessional communication, c) collaborative leadership, and d) role clarification [1].

First, participants commented on both participating, and respecting team members' contribution to collaborative decision-making $(n=4)$, which is a key attribute for the interprofessional practice competency domain of team functioning. The team functioning domain is defined as "learners understand the principles of team work dynamics and group/team processes to enable effective interprofessional collaboration" [1, p. 14]. One participant noted, "the beauty of interprofessional collaboration [is that it] makes you think differently, question ideas, and realize how compartmentalized you are at times within your own discipline" (Participant 12).

The competency domains of interprofessional communication and collaborative leadership were evident as some participants $(n=4)$ noted exchanges of information to establish group norms and processes. Another participant noted, "[I was] delightfully surprised that we [both groups of students] quickly involved ourselves with the activity and established functional group processes ... there seemed to be equal involvement amongst all the group members and equal sharing of ideas" (Participant 6). Such behaviour addresses the essence of interprofessional communication where, "learners from different professions communicate with each other in a collaborative, responsive and responsible manner" [1, p. 16]. This behaviour also demonstrates collaborative leadership qualities, as participants engaged in effective team process and decision-making [1, p. 15].

More over, participants expressed recognition and respect for the diversity of other professional roles, responsibilities, and competencies $(n=2)$. One participant 
10

Emotional Intelligence and Teamword

Lee, Bristow, \& Wong

Journal of Research in Interprofessional Practice and Education

Vol. 8.1

2018 noted, "they [participants from the other professional group] raised questions I had not previously thought of and made me re-evaluate my own understanding on the scenario ... and they were right about their logic, it's just that I haven't thought of it like this" (Participant 21). This comment reflected an understanding of "their own role and the roles of those in other professions, and use this knowledge appropriately to establish and achieve patient and community goals" [1, p. 12], which is the definition of the role clarification domain of interprofessional care.

Lastly, some logistical issues were identified $(n=4)$, including the uneven group sizes between industrial engineering and nursing students- "there was a mid-term scheduled right after the workshop ... nursing students did not show up due to preexam studying" (Participant 24) - and wanting more time for interactions and repeated exposures to similar experiences- "there is limited exposure to interprofessional collaborating in undergraduate studies, yet it is a constant requirement in the real world of both professions" (Participant 13).

\section{Discussion}

\section{Study findings}

The study aims were to: a) examine the effectiveness of a case-based interprofessional workshop for non-healthcare (industrial engineering) and healthcare (nursing) undergraduate student trainees, and b) examine the association between emotional intelligence and teamwork skills in trainees within the aforementioned undergraduate professional training programs.

\section{Was there a change in study variables after the workshop?}

While the intervention was well received by participants, and written feedback supported the hypothesis, the statistical finding from MANOVA testing did not indicate changes in emotional intelligence (including active empathic listening and emotional empathy), attitude toward interprofessional education, or teamwork skills. There are several reasons for this non-significant finding. First, it is important to note the role of statistical power in detecting statistical significance. The sample size was powered at above 80 percent and 95 percent (for MANOVA and Pearson's correlation respectively) to detect a large effect size for MANOVA, and moderate effect size for correlation with five study variables. This means that a smaller effect size demonstrated by MANOVA (partial eta-squared $=0.069$ ) [35] may require a larger sample size to reach statistical significance. In fact, the increased number of significant correlation, and increased magnitude between different aspects of emotional intelligence and teamwork skills (because correlation coefficient is one indicator of effect size [35]), suggest that some enhancement in teamwork skills may have resulted from our study intervention (findings on correlation will be discussed later).

For emotional intelligence, it tends to be stable over time as an adult, developing mostly over the span of childhood [36,37]. Increasing emotional intelligence as an adult is expected to require more effort and time. Evidence $[38,39]$ suggests a program of interprofessional training is more likely to influence behavioural changes such as teamwork skills. This means that a study with longitudinal design is preferred. 
11

Emotional Intelligence and Teamword

Lee, Bristow, \& Wong

Journal of Research in Interprofessional Practice and Education

Vol. 8.1

2018
Despite conflicting statistical findings from MANOVA and Pearson's correlation (which showed more pairs of significant correlation after study intervention), the authors believe the study intervention was effective in enhancing collaborative behaviour and emotional intelligence. The interprofessional workshop employed a case-based design, which is a type of experiential learning. In experiential learning, participants learn "from experience or from doing" [25, p. 5]. When designing the case study, a team of experts from industrial engineering, nursing, and interprofessional education intended to create dialogues and discourse when participants from diverse training background were asked to depend on one another's expertise to fulfill a common task. Such experience, when guided by structured debriefing, led to reflections and changes in attitude or behaviour about interprofessional collaboration. The authors also believe that the study population is suitable for experiential learning because interprofessional education is the most effective when learners need to "personally experience the value of the subject [interprofessional practice] in order to be motivated to learn" [40]. Based on the results of thematic analysis (see Findings), four out of six domains of interprofessional practice were noted (i.e., team functioning, interprofessional communication, collaborative leadership, role clarification). Quotes from participants showed meaningful reflections about working with people of different professional training background based on the study intervention, which indicates enhanced insight from this specific experience. For instance, for the domain of "team functioning," participants appreciated the occasion where different views came together for decision-making tasks, and reported feeling "compartmentalized" without participation from other professionals. For the domain of "collaborative leadership," participants expressed the experience of "equal involvement" and "equal sharing," which is a key feature for this domain. Because the current study did not ask for specific qualitative feedback (the "comment" section was optional in study survey), a stronger emphasis in qualitative data, such as observation or interviews, would provide further information about more domains of interprofessional collaborative competence and add richness to quantitative data.

In addition to the aforementioned factors that may have contributed to the nonsignificant MANOVA results, it is possible that the outcome measurements did not capture learning. Education experts write about the "uncontrollable variables" [41, p. 380] and suggest that the assessment of experiential learning should focus on both the process and the outcomes, not just the end product of the learning cycle [42, p. 56]. Written comments from the participants (see Findings) provide a valid description of their positive learning experiences, particularly on the development of team process and group norms.

Results also showed a non-significant but consistent decrease in ratings following the workshop (see Table 3). Although this is unexpected, such decline has been observed in the literature. This may be attributable to raised awareness of these concepts. Webb, Young, and Baumer [43] observed a decline in ratings of emotional intelligence following an emotional intelligence coaching intervention. However, participants did not provide an explanation. Wagner, Jester, Albritton, Fincher, and 
Emotional Intelligence and Teamword

Lee, Bristow, \& Wong

Journal of Research in Interprofessional Practice and Education

Vol. 8.1

2018
Moseley [44] also found a decline in self-reported medical student emotional intelligence scores. Reporting similar findings, Stratton, Saunders, and Elam suggested that "the decline in humanitarianism, enthusiasm and idealism experienced by medical students [45, p. 282]" may be attributed to the erosion of emotional intelligence through medical school and residency training, which is unlikely to be the case for participants of this study because the pre- and post-test occurred within a week. It is possible that participants experienced a decline in idealism through the experience of participating in the workshop, which mimicked real-life work experience: participants may have been reminded of the complexity of work as professionals through our case. For instance, during the workshop, industrial engineering students had to learn medical terminologies in communicating about the content of each photo. In the findings, it is shown that one participant questioned their own actions and perspectives from this experience. Further investigations are warranted to replicate this decline or explore reasons for this trend.

\section{Is emotional intelligence associated with teamwork skills?}

Confirming the hypothesis, study findings support the theory that emotional intelligence is associated with teamwork skills [13]. Given theoretical support and the moderate effect size of correlation tests ( $r$ ranged from 0.38 to 0.77 ), it is safe to assume that a significant portion of teamwork skills requires self-regulation and a perception of emotions (which are components within emotional intelligence). These moderateto-large effect sizes (e.g., $r=0.3$ being moderate and 0.5 being large) [35] are larger than those from MANOVA testing (partial eta-squared $=0.069$, which is considered to be of moderate effect size) [35]. The effect sizes provided insight about the strength of association among these variables, as well as confirmation of convergence validity between MANOVA and Pearson's correlation.

Similar findings about emotional intelligence and teamwork have been reported in the literature. A recent study conducted in medical students confirmed an overlap (shared variance) between empathy and teamwork. While the focus of Hojat et al.'s [15] study was on integrated patient care approach, the authors recognized the common denominators of interpersonal skills and an understanding of other people's needs (such as patient's needs) in integrated patient care, empathy, and teamwork. As such, collaborative skills that are interpersonal in nature, such as communication skills, are likely to be more sensitive to one's level of emotional intelligence. Certainly, further empirical validation is needed. The confirmation that emotional intelligence is correlated with teamwork skills is a significant finding because this calls for interprofessional education training beyond an approach that focuses primarily on technical and prescriptive coordination strategies, such as structured communication techniques. Empathy and interpersonal interactions are not conventional topics in most STEM undergraduate programs. These findings invite further exploration and changes in curriculum design and teaching pedagogies to potentially address this gap.

Lastly, the finding of significant correlation between emotional intelligence and team skills does not mean that individuals who simply score high on emotional intel- 
Emotional Intelligence and Teamword

Lee, Bristow, \& Wong

Journal of Research in Interprofessional Practice and Education

Vol. 8.1

2018 ligence or empathy tests are more collaborative. This is because collaborative competencies require integration of knowledge, skills, values, and attitude [34], emotional intelligence alone would not suffice.

\section{Limitations}

Key limitations of this study include a small sample size, limited exposure to interprofessional interactions based on a one-time event, self-report bias, and a lack of control for confounding variables (e.g., prior exposure to interprofessional education and teamwork experience). Also, the small sample of nursing students prevented the comparison of study variables from the two professional groups. While the comparison between the two professional groups was not an aim of this study, such comparison may have shown that emotional intelligence is worth considering in STEM training programs.

A larger sample, longitudinal methods, and other evaluative techniques, such as observations and peer feedback, require more time and resources. Thus, this limitation is a reflection of the constraints on organizational resources and constraints on students' time. Notwithstanding the limited exposure to interprofessional interactions in this study, the development and integration of an interprofessional activity that crossed two courses in different disciplines provided students with an experience that they simply would not have gained in their regular programs. For instructors and interprofessional education researchers, the limitations of this study point to the need for continued and increased support to develop a number of activities integrated into a curriculum that substantially prepares students for multidisciplinary teamwork in their future careers.

\section{Future directions}

Intervention studies are best to utilize a longitudinal, experimental design to enhance validity on whether or not these activities are effective. Nonetheless, the gaps identified in this study suggest a required focus on developing research methods to capture the influence of interprofessional activities among individuals from disciplines within and outside of healthcare. Future longitudinal studies can use the effect sizes reported in the present study (e.g., Pearson's correlation coefficient and partial eta-squared for MANOVA) as a reference point for sample size calculations. In addition to the general issues that challenge most in this field (e.g., funding for longitudinal research, scheduling conflict, competing with priorities for technical knowledge, lobbying for champions from each discipline, and the demand for wellrounded assessment of interprofessional education outcomes) [26], the gathering of professionals from within and outside of health disciplines presents unique challenges in creating relevant training objectives for all participants. So perhaps, one area for future research would be to determine if the current interprofessional education frameworks and objectives are applicable and appropriate to disciplines outside of healthcare.

The present study aims to provide ideas to support interested educators in thinking outside of the typical collaborators they come in contact with. While not every nurse 
14

Emotional Intelligence and Teamword

Lee, Bristow, \& Wong
Journal of Research in Interprofessional Practice and Education

Vol. 8.1

2018 will collaborate with an industrial engineer (and vice versa), it is important to educate trainees to understand and communicate their professional identity at work with a lay audience. This type of interaction is different from patient communication (or client communication for industrial engineers) and can be introduced at the pre-licensure level, given the diverse spectrum of professional practice in most disciplines.

From a theoretical perspective, findings from this study support the hypothesized role of emotional intelligence in teamwork skills. However, further validation and theorizing are needed to delve into specific dimensions of emotional intelligence that have the most impact on teamwork skills, echoing Clarke's study [17] (see Background). It is important to note that emotional intelligence is a trait that is stable over time. It may be more feasible to manipulate knowledge, skills, or other attitudinal items, though these changes may not be as lasting. Still, empirical support is needed to demonstrate the connection through observations of individual behaviour and team performance.

\section{Conclusions}

This study contributes to the literature by providing estimates of effect size linking emotional intelligence and teamwork. These results can be instrumental in determining education priorities for future trainees in professional training programs. More importantly, this article provides an example of an interprofessional education workshop for two professional groups with diverse training objectives and student demographics. The consistent quantitative and qualitative findings supported the effectiveness of the workshop. The experience demonstrates that the creation of relevance was possible given thorough consideration and a thoughtful planning process that involved experts from each discipline from the very beginning. The scholarship of interprofessional education should broaden to beyond healthcare disciplines.

\section{Acknowledgements}

The Mechanical and Industrial Engineering department at Ryerson University financially supported this work. Our thanks to Professor Jacob Friedman and Ms. Lynn Reynolds for supporting the interprofessional collaboration administratively. Moreover, the authors are indebted to the following individuals for their contributions to the development of the workshop's purpose and process: Dr. Howard Abrams and Shoshana Hahn-Goldberg of the Centre for Innovation in Complex Care and Dr. Jason Wong of the Stronach Regional Cancer Centre. Lastly, the authors are grateful to Aaron Bechtold for his work as research assistant.

\section{References}

1. Canadian Interprofessional Health Collaborative (CIHC). (2010). A national interprofessional competency framework. Vancouver, BC: Canadian Interprofessional Health Collaborative. URL: http://www.cihc.ca/files/CIHC_IPCompetencies_Feb1210.pdf [November 1, 2017].

2. LUMA Institute. (2012). Innovating for people: Handbook of human centered design methods. Pittsburgh, PA: LUMA Institute.

3. Simonsen, J., \& Robertson, T. (Eds.) (2013). Routledge international handbook of participatory design. New York, NY: Routledge. 
15

Emotional Intelligence and Teamword

Lee, Bristow, \& Wong

Journal of Research in Interprofessional Practice and Education

Vol. 8.1

2018
4. Gurses, A.P., \& Pronovost, P.J. (2011). Physical environment design for improving patient safety. HERD, 5(1), 3-5.

5. Mitchell, R., Parker, V., Giles, M., \& White, N. (2010). Toward realizing the potential of diversity in composition of interprofessional health care teams: An examination of the cognitive and psychosocial dynamics of interprofessional collaboration. Medical Care Research and Review, 67(1), 3-26.

6. Grumbach, K., \& Bodenheimer, T. (2004). Can health care teams improve primary care practice? JAMA, 291(10), 1246-1251.

7. Zwarenstein, M., Goldman, J., \& Reeves, S. (2009). Interprofessional collaboration: Effects of practice-based interventions on professional practice and healthcare outcomes. Cochrane Database of Systematic Reviews, 3(CD000072). doi: 10.1002/14651858.CD000072.pub2

8. Katzenbach, J.R., \& Smith, D.K. (1993). The discipline of teams. Harvard Business Review, 71(2), $111-120$.

9. Lamb, G., Zimring, C., Chuzi, J., \& Dutcher, D. (2010). Designing better healthcare environments: Interprofessional competencies in healthcare design. Journal of Interprofessional Care, 24(4), 422-435.

10. D’Amour, D., Ferrada-Videla, M., San Martin Rodriguez, L., \& Beaulieu, M.D. (2005). The conceptual basis for interprofessional collaboration: core concepts and theoretical frameworks. Journal of Interprofessional Care, 19(Suppl. 1), 116-131.

11. Salovey, P., \& Mayer, J.D. (1990). Emotional intelligence. Imagination Cognition and Personality, 9(3), 185-211.

12. Goleman, D. (1998). Working with emotional intelligence. New York, NY: Bantam Books.

13. Luca, J., \& Tarricone, P. (2001). Does emotional intelligence affect successful teamwork? Meeting at the crossroads: Proceedings of the 18th Annual Conference of the Australasian Society for Computers in Learning in Tertiary Education. Melbourne, Australia, December, 9-12.

14. Owolabi, A.B. (2012). Effect of psychological work climate and emotion intelligence on teamwork, Journal of Asian Scientific Research, 2(3), 150-158.

15. Hojat, M., Bianco, J.A., Mann, D., Massello, D., \& Calabrese, L.H. (2015). Overlap between empathy, teamwork and integrative approach to patient care. Medical teacher, 37(8), 755-758.

16. Reeves, S., Suter, E., Goldman, J., Martimianakis, T., Chatalalsigh, C., \& Dematteo, D. (2007). A scoping review to identify organizational and education theories relevant for interprofessional practice and education. Calgary, AB: Calgary Health Region.

17. Clarke, N. (2010). Emotional intelligence abilities and their relationships with team processes. Team Performance Management, 16(1/2), 6-32.

18. Emmerling, R.J., \& Goleman, D. (2003). Emotional intelligence: Issues and common misunderstandings. Issues and Recent Developments in Emotional Intelligence, 1(1). URL: http://eiconsortium.org/pdf/EI_Issues_And_Common_Misunderstandings.pdf [October 27, 2017].

19. Farh, C.I., Seo, M.G., \& Tesluk, P.E. (2012). Emotional intelligence, teamwork effectiveness, and job performance: the moderating role of job context. Journal of Applied Psychology, 97(4), 890-900.

20. Weisinger, H. (1998). Emotional intelligence at work: The untapped edge for success. San Francisco, CA: Jossey-Bass Publishers.

21. Bodie, G.D. (2011). The Active-Empathic Listening Scale (AELS): Conceptualization and evidence of validity within the interpersonal domain. Communication Quarterly, 59(3), 277-295.

22. Caruso, D.R., \& Mayer, J.D. (1998). A measure of emotional empathy for adolescents and adults [Unpublished manuscript]. Durham, NH: University of New Hampshire.

23. Luecht, R.M., Madsen, M.K., Taugher, M.P., \& Petterson, B.J. (1990). Assessing professional perceptions: Design and validation of an Interdisciplinary Education Perception Scale. Journal of Allied Health, 19(2), 181-191.

24. Hepburn, K., Tsukada, R., \& Fraser, C. (1998). Team skills scale. In E.L. Siegler, K. Hyer, T. Fulmer, \& M. Mezey (Eds.), Geriatric interdisciplinary team training (pp. 264-265). New York, NY: Springer Publishing Company.

25. Lewis, L.H., \& Williams, C.J. (1994). In L. Jackson \& R.S. Caffarella (Eds.). Experiential learning: A new approach (pp. 5-16). San Francisco, CA: Jossey-Bass.

26. Boet, S., Bould, M.D., Burn, C.L., \& Reeves, S. (2014). Twelve tips for a successful interprofessional team-based high-fidelity simulation education session. Medical Teacher, 36(10), 853-857.

27. Gardner, R. (2013). Introduction to debriefing. Seminars in Perinatology, 37(3), 166-174.

28. Braun, V., \& Clarke, V. (2006). Using thematic analysis in psychology. Qualitative Research in Psychology, 3, 77-101.

29. Weathington, B.L., Cunningham, C.J.L., \& Pittenger, D.J. (2012). Understanding business research (1st ed.). Hoboken, NJ: John Wiley \& Sons. 
16

Emotional Intelligence and Teamword

Lee, Bristow, \& Wong
30. Murphy, K.R., Myors, B., \& Wolach, A. (2014). Statistical power analysis: A simple and general model for traditional and modern hypothesis tests (4th ed.). New York, NY: Routledge.

31. Guilford, J.P., \& Frunchter, Benjamin. (1978). Fundamental statistics in psychology and education. Singapore: McGraw-Hill Book.

32. College of Nurses of Ontario (CNO). (2014). New members in the general class 2014. Toronto, ON: College of Nurses of Ontario. URL: http://www.cno.org/globalassets/docs/general/43069 _stats/new-members-in-the-general-class-2014.pdf [October 27, 2017].

33. Hango, D. (2013). Gender differences in science, technology, engineering, mathematics and computer science (STEM) programs at university. Ottawa, ON: Statistics Canada. URL: http://www.statcan.gc.ca/pub/75-006-x/2013001/article/11874-eng.pdf [November 10, 2017].

34. Interprofessional Education Collaborative Expert Panel. (2011). Core competencies for interprofessional collaborative practice: Report of an expert panel. Washington, DC: Interprofessional Education Collaborative Expert Panel.

35. Cohen, J. (1988). Statistical power analysis for the behavioral sciences (2nd ed.). Hillsdale, NJ: Erlbaum.

36. Mayer, J.D., Caruso, D.R., \& Salovey, P. (1999). Emotional intelligence meets traditional standards for an intelligence. Intelligence, 27(4), 267-298.

37. Petrides, K.V., Furnham, A., \& Mavroveli, S. (2007). Trait emotional intelligence. Moving forward in the field of EI. In G. Matthews, M. Zeidner, \& R.D. Roberts (Eds.), The science of emotional intelligence. Knowns and unknowns (pp. 151-166). New York, NY: Oxford University Press.

38. Lindqvist, S., Duncan, A., Shepstone, L., Watts, F., \& Pearce, S. (2005). Case-based learning in cross-professional groups: The development of a pre-registration interprofessional learning programme. Journal of Interprofessional Care, 19(5), 509-520.

39. Morphet, J., Hood, K., Cant, R., Baulch, J., Gilbee, A., \& Sandry, K. (2014). Teaching teamwork: An evaluation of an interprofessional training ward placement for health care students. Journal of Advances in Medical Education and Practice, 5, 197-204.

40. Cantor, J.A. (1995). Experiential Learning in Higher Education. Washington, DC: ASHEERIC Higher Education Report No. 7.

41. Ewert, A., \& Sibthorp, J. (2009). Creating outcomes through experiential education: The challenge of confounding variables. Journal of Experiential Education, 31(3), 376-389.

42. Qualters, D.M. (2010). Bringing the outside in: Assessing experiential education. New Directions for Teaching and Learning, 124, 55-62.

43. Webb, A.R., Young, R.A., \& Baumer, J.G. (2010). Emotional intelligence and the ACGME competencies. Journal of Graduate Medical Education, 2(4), 508-512.

44. Wagner P.J., Jester D.N., Albritton T.A., Fincher R.M., \& Moseley, G.M. (2005). Emotional intelligence changes during medical school. Teaching and Learning in Medicine, 17(4), 391-395.

45. Stratton T.D., Saunders J.A., \& Elam C.L. (2008). Changes in medical students' emotional intelligence: An exploratory study. Teaching and Learning in Medicine, 20(3), 279-284. 